\title{
Incentives can't buy me knowledge: The missing effects of appreciation and aligned performance appraisals on knowledge sharing of public employees
}

To be cited as: Fischer, Caroline (2020): Incentives can't buy me knowledge: The missing effects of appreciation and aligned performance appraisals on knowledge sharing of public employees. Review of Public Personnel Administration (forthcoming).

\section{Corresponding Author:}

Caroline Fischer

University of Potsdam

Social Sciences

August-Bebel-Straße 89

Potsdam 14482

Germany

Caroline.fischer.ii@uni-potsdam.de

Orcid: 0000-0001-5870-4498

Dr. Caroline Fischer is a research and teaching associate at the University of Potsdam.

In her research, she focuses on human resource management and knowledge management in the public sector. 


\section{Incentives can't buy me knowledge: The missing effects of appreciation and aligned performance appraisals on knowledge sharing of public}

\section{employees}

This study examines whether incentives affect public employees' intention to share knowledge. Tested incentives satisfy needs for either achievement or appreciation. Both treatments were tested on implicit as well as explicit knowledge sharing. A 2x3 factorial survey experiment was designed to observe within-person and between-person effects. Data were collected from public employees in the core administration and healthcare sector $(n=623)$ in 2018 . The analysis indicates that both treatments positively affect knowledge-sharing intention if it is explicit knowledge that ought to be shared. However, no effects of either treatment can be found in either type of knowledge sharing. No negative effect of the tested incentives on knowledge sharing was observed. Hence, incentives might not harm knowledge sharing but also do not pay off in organizational practice. In contrast to these motivation-enhancing human resource practices, ability and opportunity-enhancing practices should be tested to foster knowledge sharing. 


\section{INTRODUCTION}

Employees' knowledge plays an important strategic role in public organizations, which are knowledge organizations by nature. Knowledge sharing of public employees is important for providing high-quality government services (Kim \& Lee, 2006, p. 370). However, comparative studies show that knowledge is shared less in the public than in the private sector (Kim \& Lee, 2006, p. 377). It is presumed that this might, among other factors, be due to a lack of rewards systems acknowledging knowledge sharing (Vong, Zo, \& Ciganek, 2016, p. 420). Therefore, knowledge silos and incompatible channels of communication arise. Additionally, staff turnover and growing retirement rates create challenges for the preservation of individual knowledge in organizational memory. All in all, knowledge sharing of employees is needed but takes place insufficiently in the public sector. As Dawes, Cresswell, and Pardo (2009, p. 392) put it: "need to know" is the default option in public organizations, but we need to move to "need to share" to successfully cope with complex problems, which can only be tackled in networks.

Hence, we need to know how knowledge sharing can be fostered. There is disagreement around the determinants of (public) employees' knowledge sharing. The influence of tangible rewards on knowledge sharing is especially debated in the literature. Some studies show that rewards increase the knowledge-sharing activity of employees in an organization (Kim \& Lee, 2006; Wang, Noe, \& Wang, 2011; Witherspoon, Bergner, Cockrell, \& Stone, 2013); others point to the contrary and suggest that expected rewards do not or even negatively affect knowledge sharing (Bock \& Kim, 2001; Lin, 2007). This study contributes to this debate by seeking to clarify these ambiguous results.

Furthermore, studies on rewards draw implications for different leadership behaviors and management interventions. For example, Cabrera, Collins, and Salgado (2006, p. 260) explicitly mention that human resource (HR) departments should revise 
performance appraisal instruments to align rewards with knowledge sharing, even though they have not tested this implication of their study.

Hence, the next step is to analyze whether such changes would really affect employees and lead to different knowledge-sharing behavior. Accordingly, the following research question is posed: How do incentives affect knowledge sharing of public employees? This study uses an experimental approach to test the effect of different interventions on public employees' knowledge sharing. A factorial survey experiment was designed to test the effects of tangible and intangible incentives on the intention to share different kinds of knowledge. Data were collected from German public employees in the core administration and the healthcare sector $(n=623)$ in 2018 using an online panel. To date, knowledge sharing in the public sector has only been assessed for particular groups, like the police (Luen \& Al-Hawamdeh, 2001) or teachers (Agyemang, Dzandu, \& Boateng, 2016). However, a more general view analyzing different organizations in the public sector is still missing. Furthermore, by using a sample of real public employees, this study also overcomes weaknesses of experiments with students, which are dominant in public administration research to date but lack external validity and experimental realism (Bouwman \& Grimmelikhuijsen, 2016; James, Jilke, \& van Ryzin, 2017).

The results suggest that the intention to share knowledge is neither affected by the tested treatments nor by the kind of knowledge shared. No difference in the effect of the tested treatments was observed. Similarly, explicit knowledge sharing does not differ from implicit knowledge sharing. However, an adverse effect of tangible incentives on knowledge sharing that other research reports (e.g., Bock \& Kim, 2001) is not supported by this study.

This study adds three critical contributions to the public administration and human resource management (HRM) knowledge base, including research on knowledge 
management, incentives, and working behavior in general. First, this study contributes to the beginning literature on knowledge sharing in the public sector, which has mainly focused on a macro- or meso-level perspective to date (Bundred, 2006; Currie \& Suhomlinova, 2006; Dawes et al., 2009; Siciliano, 2017). However, knowledge management always relies on humans as carriers of knowledge, and therefore a microlevel perspective is needed too, mainly to discuss practical implications for public management and HRM. Second, this study adds theoretical evidence to the (weak) significance of valence in human behavior formation and a possibly stronger influence of instrumentality and expectancy on knowledge sharing. In that regard, this study contributes to findings on the influence of motivation-enhancing rewards and HR practices in contrast to ability-enhancing and opportunity-enhancing ones. Third, by revealing no negative influence of tangible incentives on knowledge sharing and no major difference between the tangible and intangible treatments, this study also adds to the discussion on the appropriateness and necessity of tangible rewards.

This article is organized as follows. First, the state of research on knowledge sharing and its determinants is described. Second, a theoretical model is presented and hypotheses are derived, which are tested using an experimental approach. This method is described in the third section. Subsequently, the results are presented and discussed.

\section{STATE OF RESEARCH}

Knowledge sharing is the exchange of knowledge among individuals, teams, units or organizations (Paulin \& Suneson, 2012). It is the basis of and a subprocess in knowledge management of an organization. Ultimately, knowledge sharing is seen as a determinant of individual and organizational performance (Henttonen, Kianto, \& Ritala, 2016; Kang, Kim, \& Chang, 2008). Usually, knowledge sharing describes a 
unidirectional exchange of knowledge, such as when one colleague explains a procedure to another. Nonetheless, knowledge sharing can also take place in a bi- or even multidirectional way, for instance in team meetings. However, a distinction has to be made between donating and receiving knowledge (Sandhu, Jain, \& Ahmad, 2011, p. 209). In this study, knowledge sharing is defined as a unidirectional donation of knowledge.

According to Bock and Kim (2001, p. 1112) "sharing knowledge is often unnatural [...]. Hoarding knowledge and looking suspiciously upon knowledge from others is the natural tendency." At the same time, knowledge sharing requires effort on the part of these knowledge owners. Hence, according to Bartol and Srivastava (2002), "What's in it for me?" is their central question before sharing their knowledge. Therefore, Koenig (1999, p. 24) advises: "Effective knowledge sharing requires rewarding those who input information into the system and who contribute something useful." Hence, the costs that arise from knowledge sharing should be compensated by benefits an employee can gain from this work behavior. The literature discusses benefits, such as icentives, as one determinant, among others, on knowledge sharing.

\section{Effects of incentives on knowledge sharing}

Multiple determinants influence knowledge sharing. These determinants can be considered either intra-personal (e.g., traits, skills, motivation) or extra-personal factors (e.g. rewards, infrastructure, leadership). Particularly in the public sector, (missing) extra-personal factors are perceived as higher barriers to knowledge sharing than intrapersonal factors (Hansen, 1999, p. 109; Sandhu et al., 2011, p. 219). Among others, external factors can be rewards (Amayah \& Nelson, 2010; Bock \& Kim, 2001, pp. 1114-1115; Kang et al., 2008, p. 1561), infrastructure (Andreeva \& Kianto, 2012; 
Hansen, 1999), leadership (Bryant, 2003; Srivastava, Bartol, \& Locke, 2006), organizational structure (Henttonen et al., 2016, p. 759) or culture (Witherspoon et al., 2013, p. 265).

As in other areas, such as performance pay (Bellé, 2015) or coproduction (Voorberg, Jilke, Tummers, \& Bekkers, 2018), the influence of rewards on knowledge sharing is debated in the literature. It has been shown that monitoring (e.g. controlling via performance measures) and rewards increase the knowledge-sharing activity of employees in an organization (Kim \& Lee, 2006; Wang et al., 2011; Witherspoon et al., 2013). However, Bock and Kim's (2001) results suggest that expected rewards do not affect knowledge sharing, but expected associations with colleagues and expected contributions to an organization's performance do. Similarly, Lin (2007) showed that expected rewards did not influence knowledge-sharing intention, but reciprocal benefits from co-workers did. However, these results are based on survey research and the effects of rewards have not been tested experimentally yet.

The results of Bock and Kim (2001) and Lin (2007) indicate another important external determinant of knowledge sharing: the quality of social interaction and the climate in a team or organization. Kakar (2018) revealed that whereas task conflicts impact knowledge sharing positively, high levels of relationship conflicts in a team are not conducive to sharing knowledge. Similarly, Behringer, Sassenberg, and Scholl (2017, p. 16) observe that a higher identification of employees with a group, such as their team or organization, leads to a higher intention to share knowledge. It has also been shown that reputation can be perceived as an incentive to share one's knowledge (Yu, Lu, \& Liu, 2010).

Especially in online communities, a so-called 'gift culture' has been described and related to sharing open code. The social status in a community is determined by 
which and how much knowledge someone gives away (Raymond, 1999). In the public sector, Sandhu et al. (2011) found a lack of recognition of knowledge sharing to be a major barrier to sharing knowledge. These different results of co-workers' influence on knowledge sharing point to the vital impact of appreciation and recognition. However, it has not been tested in an experimental way to date, whether appreciation can be used as an intangible incentive to foster knowledge sharing. Hence, appreciation is analyzed as an intangible incentive in this study and compared to a benefit in the performance appraisal as a tangible incentive.

However, it is debated in the literature, whether these different determinants of knowledge affect the sharing of every kind of knowledge similarly. Hence, sharing of different kinds of knowledge might be fostered or not and to a different degree by appreciation as an intangible incentive and performance appraisal benefits as tangible incentives.

\section{Effects of knowledge types on knowledge sharing}

It is assumed that the type of knowledge that ought to be shared affects whether and how knowledge is shared (Ipe, 2003). Among other categories, knowledge is often separated into explicit and implicit knowledge. Explicit knowledge can be codified, stored, and transferred and is therefore independent of individuals (Polanyi, 1962), for instance, factual knowledge (know-what). Implicit knowledge is hidden and unconscious, such as experiences (know-how) or knowledge about where to find knowledge (transactive knowledge, know-where). The literature on knowledge sharing commonly assumes that this implicit knowledge can be explicated and shared (e.g. Levallet \& Chan, 2016). Nevertheless, it is mentioned that "tacit knowledge, by its very nature, is difficult to transfer" (Amayah, 2013, p. 454; similarly Hau, Kim, \& Lee, 
2016; van Wijk, Jansen, \& Lyles, 2008). Law, Chan, and Ozer (2017) suggest a differing influence of extrinsic and intrinsic motivators on implicit and explicit knowledge sharing. Hence, the type of shared knowledge might explain the ambiguous findings on the effect of rewards on knowledge sharing so far. The present study investigates treatment effects on explicit as well as implicit knowledge in order to prove this assumption.

\section{Effects of individual characteristics on knowledge sharing}

Internal determinants of knowledge sharing are individual factors like tenure (Gilson, Lim, Luciano, \& Choi, 2013; Lin \& Lee, 2004), traits (Kang et al., 2008, p. 1561), skills (Sandhu et al., 2011, p. 210), and motivation (Henttonen et al., 2016, p. 759; Witherspoon et al., 2013, p. 265). It has been shown that public employees score high in knowledge-sharing motivation (e.g. Hansen, 1999, p. 109). Different motives have been identified for shaping the knowledge-sharing motivation of public employees, namely altruism and growth, appreciation, and tangible rewards (Fischer, $2018 \mathrm{~b}$ ). These motives are used as a basis for creating interventions to foster knowledge-sharing behavior in this study. These interventions form a situational influence that can activate personal motives, resulting in appropriate intention and behavior. It is focused particularly on the motives of appreciation and tangible rewards because they constitute extrinsic motives and can thus be manipulated by external interventions. In contrast, altruism and growth represent intrinsic motives and are less easily influenced by incentives.

\section{THEORETICAL MODEL}

Process theories of motivation and volitional theories provide the basis for the 
theoretical model used in this study (figure 1). They shape the process of human behavior in subsequent steps: motivation as an interaction of personal motives and situational influence, intention, and behavior. In the context of this study, this implies that motives and situational determinants form knowledge-sharing motivation (Witherspoon et al., 2013). Personal motives are supposed to be lasting characteristics, which are activated by situational influences. Situational influences serve as independent variables in this study.

Knowledge-sharing motivation further affects but is not the only determinant of knowledge-sharing intention and, subsequently, intention leads to knowledge-sharing behavior. However, real behavior cannot be measured in surveys. Thus only knowledge-sharing intention was used as a dependent variable in this study.

[Figure 1 here]

The basic rationale of this study's theoretical model is an assumption from behavioral theory, namely that employees perform behavior if an expected outcome fits their needs. Vroom's expectancy theory (1967) describes the cognitive process of how an individual decides how to behave. This behavioral intention is formed by three interacting parameters: valence, instrumentality, and expectancy. This study focuses on the effect of valence. According to Vroom, individuals rate the value of a behavioral outcome (valence). This is not (only) action as such but also outcomes resulting from this action, such as getting a reward. If this valence is positive, an individual will put more effort into a work behavior to reach the expected outcome in cases where the individual expects to be able to behave in such a way (expectancy) and it is certain that the preferred outcome will be achieved (instrumentality). Consequently, such a 
perceived outcome motivates an individual to work toward this goal. A similar explanation is offered by the inducement-contribution model, which focuses more on support and incentives provided by an organization (inducement) to encourage their employees to reach their goals and thereby contribute to the organization (contribution) (March \& Simon, 1958).

Incentives represent behavioral outcomes and are thereby "intensifiers in anticipation" (Wiswede, 2012, p. 64). They are motivation-enhancing HR practices (Chuang, Jackson, \& Jiang, 2016, p. 528). If a task required by an organization does not produce the preferred outcomes by itself or the motivational force to complete a task as such (intrinsic motivation), incentives can be used to produce outcomes preferred by the employees in order to enhance the motivation to perform these tasks (extrinsic motivation). These incentives can be differentiated into tangible incentives, such as a financial bonus, and intangible incentives, such as kudos from a colleague. In a process theory of motivation, incentives represent one aspect of situational influence on the path from motivation via intention formation to behavior.

How an individual rates a specific behavioral outcome, hence the value of an incentive, can be explained by human needs, such as those for power, achievement, and appreciation (McClelland, 1987). If an incentive satisfies a need that is of importance to an individual, it will be rated higher in valence. This study tests interventions that satisfy the need for either achievement or appreciation.

Social exchange theory provides a theoretical foundation for the effect of a satisfied need for appreciation on knowledge-sharing behavior (Blau, 1964). The theory expects that humans will behave rationally and will perform a particular behavior if they expect to be 'repaid' by social interaction. Translated into the context of knowledge sharing, this assumption of reciprocity means that a person will share knowledge if the 
knowledge receiver also shares knowledge in the future, or provides another social exchange, like recognition of the sharer's reputation or a token of esteem. Consequently, appreciation can serve as an intangible incentive fostering knowledge sharing (Di Gangi, Wasko, \& Tang, 2012, p. 3). Hence, the following hypothesis is derived: H1: An appreciation intervention positively affects knowledge-sharing intention. An exchange relationship must involve not only social but also economic exchange, hence tangible incentives. A person is expected to engage in exchange for his or her economic profit. An employer compensates an employee for performing work duties through the wages earned. If additional tasks are supposed to be carried out, they can be fostered by additional remuneration.

Whereas the need for appreciation can be satisfied directly by co-workers, the need for achievement is usually satisfied through compensation by a superior. A financial reward, or as in this study, a positive performance appraisal, has to be granted by a higher-ranking colleague. This might produce the opinion that knowledge has to be shared publicly and verifiably, hence in a visible way. Accordingly, Zhang, Pablos, and Zhou (2013) found that the positive effect of incentives on knowledge sharing is stronger when employees perceive the visibility of their knowledge sharing as high. Since explicit knowledge can be made visible more easily through codifying than through implicit knowledge, it is further supposed that:

H2: An achievement intervention positively affects knowledge-sharing intention if explicit knowledge is shared.

Several studies show that social interaction as an emotional and community-related benefit of knowledge sharing has a higher influence on knowledge sharing than a 
reward in the form of a personal benefit (Amayah, 2013, p. 463; Cabrera et al., 2006, p. 259). Bock and Kim (2001, p. 1119) even found that expected (tangible) rewards affect knowledge sharing negatively (similarly Hau et al., 2016). Therefore, it is suggested that the appreciation treatment will have a stronger positive effect on knowledge sharing than the achievement treatment:

H3: An appreciation intervention has a stronger positive effect on knowledge-sharing intention than an achievement intervention.

\section{METHOD}

An experimental approach is used to test the effect of incentive interventions on public employees' knowledge-sharing intention and behavior. These interventions apply tangible and intangible incentives that satisfy either the need for achievement or the need for appreciation. A survey experiment based on vignettes was designed. The experiment was preregistered in the open science framework (Fischer, 2018a). ${ }^{1}$

An experimental approach has already been proven useful in the context of knowledge-sharing behavior, as Cress and Hesse (2004) and van Baalen, van Dalen, and van Malsen (2013) used experiments to analyze the effects of social dilemmas and

\footnotetext{
${ }^{1}$ The article differs from the pre-registration in some aspects: (1) Hypotheses were restructured and differ slightly in wording. However, the tested relationship remains the same. (2) Knowledge-sharing behavior was excluded as a dependent variable, because the data collection using open-ended questions failed. It was the initial idea to use open-ended questions as real-effort tasks in the survey experiment, but due to a strong order effect participants put more effort in answering to the baseline vignette than to the treatment vignettes. (3) Due to a missing normal distribution, data were not analyzed by parametric but by non-parametric tests. Additionally, equivalence tests were included to prove the absence of effects when significance tests suggested insignificant results.
} 
relational conflicts on knowledge-sharing behavior. They conducted lab experiments with students, which are criticized for not being valid externally in several disciplines (Bello, Leung, Radebaugh, Tung, \& van Witteloostuijn, 2009; Hanel \& Vione, 2016; Henry, 2008; Peterson, 2001). This study overcomes this weakness by using a survey experiment to reach a special population, namely public employees. It was expected that they would behave in a different way than students because behavior builds on previous experience, education, and life-stage characteristics. In this case, previous knowledgesharing situations at the workplace might influence future knowledge sharing (Gilson et al., 2013). Further, knowledge sharing is influenced by the educational level, which is homogenous and higher among students (Lee \& Al-Hawamdeh, 2012). Finally, selfperception and self-confidence, which usually develop over the life course, was also found to influence knowledge sharing (Yeo \& Marquardt, 2015).

The chosen vignette approach has already been proven useful in the context of knowledge management by Di Gangi et al. (2012) to analyze typical communication channels for different types of knowledge.

[Table 1 here]

In a $2 \times 3$-factorial design, each participant is randomly assigned to a set of three vignettes. Randomization is completed after participants have started to answer the survey, based on their respondent ID. The vignettes incorporate all independent variables: implicit/explicit knowledge, the achievement or the appreciation treatment (see table 1). Each set contains vignettes on either explicit knowledge or implicit knowledge (between-subject design). The first vignette in each set is a baseline vignette; the following two vignettes present in a randomly assigned order an achievement 
treatment and an appreciation treatment (within-subject design).

Performance appraisals are used as the achievement treatment ("You know that all shared information improves your performance appraisal"). Performance appraisals serve as a proxy for further rewards because it seems unrealistic in the public sector to offer bonuses or other tangible incentives directly depending on a person's knowledgesharing behavior. This decision should address the problem that vignette experiments are frequently criticized for being unrealistic and thereby lacking external validity (Aguinis \& Bradley, 2014, p. 361).

The appreciation treatment is operationalized by offering explicit appreciation by co-workers without illustrating further how this appreciation occurs ("You know your co-workers appreciate your knowledge sharing"). A rather superficial description is used here because in every team appreciation is shown in different modes (e.g., explicit verbal expression, good team climate, respectful intercourse) and the vignette should not be too restrictive.

Knowledge-sharing intention is used as the dependent variable. It is formed as the arithmetic mean index of two rating items constructed as 5-point Likert scales. The items read as: "I will share this knowledge with my co-workers." and "I would like to share this knowledge with my co-workers." The former item represents the futureoriented and behavioral part of intention and the latter represents the motivational part of intention. Both items are based on scales on knowledge-sharing intention used by, for example, Bock and Kim (2001) and Lin (2007). They are adapted to the experimental context. Both items correlate highly and are therefore compiled into an index for further analysis. Cronbach's alphas for knowledge-sharing intention range between 0.818 (vignette 6) and 0.9711 (vignette 3).

Data are collected from a sample of 1886 employees in the German core public 
service and health sectors. Two different fields are analyzed in the public sector to produce more general results. To date, knowledge sharing in the public sector has only been assessed for special groups, like the police (Luen \& Al-Hawamdeh, 2001) or teachers (Agyemang et al., 2016). However, a more general view analyzing different public sectors is still missing.

An online panel is used to recruit the sample so that people can be interviewed in their private time and not at the workplace. Therefore, lower social desirability bias and more honest answers can be expected. Additionally, the online panel enables a diverse sample from more than just a few organizations. and no or at least fewer multilevel problems can be expected, such as the organizational culture dominating the results. The disadvantages of samples drawn from online panels are self-recruitment into the panel and learning effects leading to 'professionalized' interviewees. Nevertheless, self-recruitment into the sample would have taken place with another sampling strategy anyway. Participants are incentivized with one Euro per 10 minutes of survey time, which is the amount usually used by the panel.

From a sample of 1886 people, 767 responded (40.6\%). Screen-outs according to occupation and early dropouts add up to 56 cases. A so-called 'poor quality question' is used to screen out participants who are unaware, which leads to the exclusion of another 67 cases, and four other cases are excluded because of streamlined answering behavior. Eleven cases are excluded, which answered fewer than two vignettes in the survey. 629 cases remain, which means a return rate of $33 \%$ from the initial sample. The randomized assignment to four groups of participants (two sets of vignettes, with two versions of the ordering) leads to a distribution from 119 to 149 participants per treatment group. Preliminary power analysis for a between-subject analysis using t-tests $(d=0.2$, alpha $=0.1$, power $=0.8)$ suggests a total sample size of about 450 cases, which 
has been reached.

From the final sample of 629 participants, 314 work in the German core public service. The majority of them work on the local (38\%) or state level (33\%). Participants from the core public service are for the most part employed in the intermediate (43\%) and executive public service (34\%). 315 participants work in the health sector. Only $31 \%$ of these are employed in the public health sector. However, the difference between the public and private health sectors is only based on legal ownership and this distinction has been criticized for being too simplistic (Rainey and Bozeman 2000). Employees in the health sector perform a public task and serve the public interest. Both subsamples are chosen to cover a broad range of different occupations in the public sector.

As can be seen from Table 2, the majority of the participants are female $(61 \%)$, as is common in the German public sector. The mean age is 45 years and participants have a tenure of 20 years on average. $29 \%$ of them have a supervisory status and only a few are employed on a fixed-term contract (5\%). The majority of participants have completed a vocational education (62\%); $24 \%$ of the participants have a Master's degree.

[Table 2 here]

The completed experiment is analyzed using non-parametric significance tests. Every part of the analysis is described in more detail in the following section.

\section{ANALYSIS AND RESULTS}

Table 3 gives a short overview of the descriptive statistics. The arithmetic means of the 
dependent variable' knowledge-sharing intention' already suggest that this variable is not normally distributed. A Shapiro-Wilk test acknowledges this presumption. Therefore, non-parametric significance tests have to be conducted.

The high means for knowledge-sharing intention might be a consequence of socially desirable answering. However, other studies show high levels of knowledge sharing too, both self-reported by employees and reported by team leaders (Chuang et al., 2016, p. 538). Regardless, high mean values of baseline knowledge-sharing intention point to a possible ceiling effect. Hence, knowledge-sharing intention might already be at the highest level and cannot be fostered because it cannot increase anymore. However, the values of knowledge-sharing intention cluster not around the highest possible score (5) but only around the higher end of the scale $($ mean=4.26) and there is still enough variance in answering behavior $(\mathrm{SD}=.79)$ to observe an increase of knowledge sharing due to the used treatments. Even if a ceiling effect is on hand in this study, the following analysis will reveal null effects. Hence, ceiling effects, which usually lead to an inflation of error type 1 (false significant effects) (Austin \& Brunner, 2003), should not have harmed the results.

[Table 3 here]

The following paragraphs report results on the conducted within-analysis. Hence, it is described whether individual participants differ in their answering behavior in response to different treatments. These analyses are carried out by using Wilcoxon signed-rank tests. All in all, the analysis yields mixed results. Knowledge-sharing intention is significantly higher with both treatments (appreciation/achievement) than in the control group when sharing explicit knowledge. Even though effect sizes (Cohen's d) are 
relatively small. Therefore, the analysis is extended by equivalence tests (two one-sided signed-rank $)^{2}$ to provide confidence for the existence of a meaningful yet small effect, as well as support for the lack of a meaningful effect (Lakens, 2017) ${ }^{3}$. Table 4 specifies all results.

[Table 4 here]

\section{The influence of appreciation (hypothesis 1)}

If the data are analyzed regardless of the kind of knowledge shared, knowledge-sharing intention is higher when appreciation is offered $(4.27+/-0.82)$ as opposed to offering no treatment $(4.26+/-0.79)$. It significantly increases by 0.013 points on a scale from one to five $(\mathrm{Z}=1.647, \mathrm{p}=0.096, \mathrm{~d}=0.015$, bootstrapped confidence interval $(\mathrm{CI})-0.035$ to $0.065)^{4}$. Equivalence testing shows that this small but significant effect is at the same time partly equivalent $(\mathrm{Z} 1=0.35, \mathrm{p}=0.36 ; \mathrm{Z} 2=3.65, \mathrm{p}=0.0001)$ and, therefore, there is no relevant treatment effect.

Analyzing different kinds of shared knowledge more closely shows that these results differ according to the kind of knowledge shared. Participants report a significantly higher intention to share their knowledge when offered appreciation from their colleagues $(4.31+/-0.8)$ as opposed to no additional benefit $(4.23+/-0.05)$, when

\footnotetext{
${ }^{2}$ Two one-sided equivalence tests test whether an effect falls within an upper and a lower equivalence bound and are therefore statistically smaller than any effect deemed worthwile. To perform two onesided tests for equivalence in Stata, the package 'tost' by Alexis Dinno is used.

${ }^{3}$ Significant eqivalence tests show that an effect size (d) is to small to matter in practice.

${ }^{4}$ Because the variables are not normally distributed, bootstrapped confidence intervals may be preferred (Kelley (2005); Algina, Keselman, and Penfield (2006)).
} 
explicit knowledge is shared. This means a statistically significant increase of 0.075 points on a scale from one to five $(\mathrm{Z}=3.231, \mathrm{p}=0.001, \mathrm{~d}=0.09$, bootstrapped $\mathrm{CI} 0.027$ to 0.160). Again, equivalence testing shows that this small but significant effect is at the same time partly equivalent $(\mathrm{Z} 1=-1.23, \mathrm{p}=0.89 ; \mathrm{Z} 2=5.23, \mathrm{p}=0.00)$. Thus there is no relevant treatment effect.

Analyzing the data on implicit knowledge sharing leads to insignificant results (appreciation vs control group: $\mathrm{Z}=-1.064, \mathrm{p}=0.287$ ). Equivalence testing shows partial equivalence as well $(\mathrm{Z} 1=3.06, \mathrm{p}=0.001 ; \mathrm{Z} 2=0.94, \mathrm{p}=0.18)$. Hence the difference between the two groups is trivial. Therefore, Hypothesis 1a has to be rejected, because effects are either insignificant or of irrelevant size.

\section{The influence of achievement (hypothesis 2)}

Knowledge-sharing intention is significantly higher when offering a benefit in the form of a performance appraisal (achievement treatment) $(4.26+/-0.8)$ compared to no benefit $(4.23+/-0.8)$ only when explicit knowledge is shared. This means a statistically significant increase of 0.039 points on a scale from one to five $(\mathrm{Z}=1.816, \mathrm{p}=0.069$, $\mathrm{d}=0.048$, bootstrapped CI -0.025 to 0.121 ). However, according to equivalence testing, the two groups are partly equivalent $(\mathrm{Z} 1=0.18, \mathrm{p}=0.43 ; \mathrm{Z} 2=3.82, \mathrm{p}=0.0001)$. Hence, the data does not support Hypothesis 2.

Similarly, knowledge-sharing intention is not affected by the achievement treatment, when implicit knowledge is shared (achievement vs control group: $Z=0.335$, $\mathrm{p}=0.738)$.

\section{Difference in the influence of achievement and appreciation (hypothesis 3)}

Concerning Hypothesis 3, no significant difference can be shown between the two 
interventions $(\mathrm{Z}=-0.242, \mathrm{p}=0.81)$ regardless of which knowledge is shared. Looking at both types of knowledge separately shows that there is neither a significant difference nor equivalence between the two groups. Hence, data do not support Hypothesis 3 .

Last but not least, results on the conducted between-subject analysis are reported. This analysis describes whether participants differ in their answering behavior in response to the same treatment. Wilcoxon rank-sum tests reveal that differences between explicit and implicit knowledge sharing are not significant (Table 5).

Therefore, Hypothesis 2 is again not supported, as the achievement treatment has not different effect on different kinds of knowledge.

[Table 5 here]

\section{DISCUSSION}

This study's results suggest a missing influence of tangible and intangible incentives that could satisfy the needs for achievement and appreciation respectively on public employees' knowledge-sharing intention. First of all, it needs to be discussed whether there is indeed no substantive effect of the tested treatments, as suggested by the results, or whether knowledge-sharing intention of public employees is already that high, that it cannot increase anymore and any treatment would have been without effect (ceiling effect). Former studies do not suggest that public employees, in general, intend always to share all their knowledge so that a maximum of knowledge-sharing intention is already reached at the baseline level (Kim \& Lee, 2006, p. 377; Tuan, 2019, p. 565). Former studies using the chosen items to measure knowledge-sharing intention do also not find a ceiling effect based on this measurement instrument (Bock \& Kim, 2001; Lin, 2007). Additionally, from a statistical point of view, values of knowledge-sharing 
intention leave enough scope to observe an increase based on the tested treatments. Hence, it is supposed here, that no ceiling effect occurred and the results indeed imply a missing effect of the tested treatments on public employees' knowledge-sharing intention.

It was suggested in this study that valence, hence the individual value of an expected outcome, has a major influence on intention formation. However, as no difference could be shown in the effect of the tested treatments on knowledge-sharing intention (tangible and intangible incentives), and supposing that the two management practices are not valued in the same way by the participants, the valence of an offered incentive seems not to have a strong influence on knowledge sharing. However, this result contradicts previous results, which recognize a significant difference between tangible and intangible incentives in the context of knowledge sharing (Bock \& Kim, 2001; Lin, 2007).

This result might be explained by two other factors shaping behavioral intention formation: instrumentality and expectancy (Vroom, 1967). Instrumentality is the belief that one will receive an incentive when the corresponding expectation is met. Hence, when an individual is certain to receive an incentive for sharing knowledge, he or she is more likely to share. The null results might indicate that participants perceive no certainty on receiving the offered incentives. Here, former negative experiences might determine this perception. For example, incentives might have been offered for a certain performance but not paid out, only to a restricted group of employees or according to rules that have been decided ex post.

Expectancy might also play a role in this missing effect of incentives on knowledge sharing, which is the belief that an individual's effort will lead to the achievement of a desired goal. As sharing knowledge is often perceived as complex and 
costly (Hau, Kim, Lee, \& Kim, 2013, p. 357), individuals might feel that they have only a minor ability to share knowledge. Such a minor ability might be due to time constraints and pressing work tasks that are perceived as more important, due to missing self-confidence into own communication competencies or actual missing competencies in communicating complex knowledge.

This assumption leads to the most important and noteworthy implication of this study's results, namely that an entirely different approach has to be taken to foster knowledge sharing. Motivation-enhancing interventions might only have a minor influence on actual knowledge sharing. Hence, knowledge sharing might not be a question of will, but rather of skill (or in Vroom's words: expectancy). It seems that knowledge-sharing intention of public employees is high but, referring to results by Tuan (2019) and Bock and Kim (2001), not fully translates into high knowledge-sharing behavior. Whereas a behavioral intention is formed mainly based on the motivation to behave in a certain way, abilities and opportunities come in later and affect to which extent intention translates into actual behavior.

Siemsen, Roth, and Balasubramanian (2008, p. 427) refer to the motivationability-opportunity framework and note that "changes in motivation only affect behavior if motivation is the constraining factor; they have little or no impact if either opportunity or ability is constraining." Hence, opportunity- and ability-enhancing human resource practices may have a more substantial effect on knowledge sharing, which should be analyzed in future research.

Ability here entails an employee's competency in editing wikis or another kind of database, for example, or in assessing which knowledge is worth sharing. Training on using knowledge management instruments and technology might have an abilityenhancing impact. Opportunity also refers to external influences, such as providing the 
time and place to share knowledge (Wells \& Lesser, 1999, p. 22). Opportunityenhancing practices might include the development of organizational structures or infrastructures that allow for easier knowledge sharing.

This result may be specific to the public sector, as infrastructure and organizational structure are perceived as higher barriers to knowledge sharing than individual motivation there (Sandhu et al., 2011). Vermeeren (2017) even states that ability- and opportunity-enhancing practices are more strongly related to performance outcomes in the public sector than motivation-enhancing practices, but does not analyze this assumption in the context of knowledge sharing. Especially, low digital competencies might affect knowledge-sharing behavior in the public sector negatively (Sandhu et al., 2011).

Furthermore, it was suggested that the kind of knowledge shared might explain differing results on the effects of incentives in the literature so far. It was supposed that explicit knowledge is easier to share and to foster by incentives. However, the data does not support these assumptions. This result might be based on the operationalization of implicit and explicit knowledge, and future research should analyze other forms of implicit and explicit knowledge.

\section{CONCLUSION}

In this study, an experimental approach was used to test the effect of tangible and intangible incentives on public employees' knowledge-sharing intention. The results suggest that their intention to share knowledge is not substantially affected by the kind of knowledge shared or an offered incentive. No difference in the effect of the tested treatments (tangible incentive: achievement through a higher performance appraisal; intangible incentive: appreciation by colleagues) was observed. Both treatments showed 
no significant effects on knowledge sharing, explicit as well as implicit knowledge sharing. However, an often-reported adverse effect of tangible incentives on knowledge sharing could also not be supported by this study.

Some limitations have already been mentioned throughout the study. The vignette design also entails some limitations. Vignettes present only hypothetical situations and it is not possible to measure actual knowledge-sharing behavior. Potentially, the effect of management practices that foster knowledge-sharing behavior can be better observed in lab experiments or even ethnographically.

Furthermore, only two specific treatments are analyzed here. Hence, the results do not imply that other incentives would not have a stronger influence on knowledge sharing. Last but not least, a possible ceiling effect was already mentioned. Future studies should test, whether an adapted item wording and the use of extended answering scales (e.g. 7 or 9-point Likert scales) are more appropriate to measure knowledgesharing intention.

The current study offers several theoretical and practical contributions. It adds theoretical evidence to the significance of valence, instrumentality, and expectancy, as parameters shaping the behavioral intention to share knowledge (expectancy theory). This study's results suggest that the valence of an offered reward does not play a major role in determining knowledge-sharing intention, whereas instrumentality and expectancy might be of more importance. Future research should test the influence of instrumentality and expectancy in terms of the impact of rewards on knowledge sharing.

This study suggests that motivation-enhancing rewards do not considerably affect knowledge sharing. Hence, knowledge sharing in the public sector might not be a question of will, but rather of chances and skill. Opportunity- or ability-enhancing practices might have a more substantial influence on knowledge sharing in the public 
sector, as already suggested by Vermeeren (2017) regarding general performance in the public sector. Future research should analyze the effects of these interventions on knowledge sharing.

Concerning the discussion around the ability of incentives to foster knowledge sharing, this study did show that tangible incentives do not negatively influence knowledge sharing. Furthermore, no significant difference between tangible and intangible incentives could be observed. Hence, on the one hand, tangible rewards might not be as harmful as discussed; on the other hand, costly incentives might not be worth the investment. Future research may test this result on other kinds of incentives and analyze how rewards affect knowledge-sharing behavior in field studies.

Last but not least, this study adds to a beginning literature on knowledge management in the public sector and links public administration literature with the literature on knowledge management and knowledge sharing from a micro-level perspective. Literature on knowledge management in public administration is rare and mainly focuses on a macro- or meso-level perspective (Bundred, 2006; Currie \& Suhomlinova, 2006; Dawes et al., 2009; Siciliano, 2017). However, knowledge management always relies on humans as carriers of knowledge and therefore a microlevel perspective is highly needed.

For practitioners, the results imply that restraints concerning tangible rewards might not be suitable, but intangible incentives like appreciation might be less costintensive and have the same (weak or missing) impact on knowledge sharing. However, based on possible high knowledge-sharing intentions but missing knowledge-sharing behavior of an organizations' employees, practitioners should analyze first, whether motivation-enhancing practices could actually affect knowledge sharing or whether ability-enhancing or opportunity-enhancing practices are more suitable. When 
knowledge-sharing intention is low, motivation-enhancing instruments such as incentives might fit. When intention is already high, abilities and opportunities have to be increased to foster actual knowledge sharing. 


\section{References}

Aguinis, H., \& Bradley, K. J. (2014). Best Practice Recommendations for Designing and Implementing Experimental Vignette Methodology Studies. Organizational Research Methods, 17(4), 351-371. https://doi.org/10.1177/1094428114547952

Agyemang, F. G., Dzandu, M. D., \& Boateng, H. (2016). Knowledge sharing among teachers: The role of the Big Five Personality traits. Journal of Information and Knowledge Management Systems, 46(1), 64-84. https://doi.org/10.1108/VJIKMS-12-2014-0066

Algina, J., Keselman, H. J., \& Penfield, R. D. (2006). Confidence Interval Coverage for Cohen's Effect Size Statistic. Educational and Psychological Measurement, 66(6), 945-960. https://doi.org/10.1177/0013164406288161

Amayah, A. T. (2013). Determinants of knowledge sharing in a public sector organization. Journal of Knowledge Management, 17(3), 454-471. https://doi.org/10.1108/JKM-11-20120369

Amayah, A. T., \& Nelson, F. F. (2010). Knowledge sharing: Types of knowledge shared and rewards. 29th Annual Midwest Research-to-Practice Conference in Adult, Continuing, Community and Extension Education.

Andreeva, T., \& Kianto, A. (2012). Does knowledge management really matter?: Linking knowledge management practices, competitiveness and economic performance. Journal of Knowledge Management, 16(4), 617-636.

Austin, P. C., \& Brunner, L. J. (2003). Type I Error Inflation in the Presence of a Ceiling Effect. The American Statistician, 57(2), 97-104. https://doi.org/10.1198/0003130031450

Bartol, K. M., \& Srivastava, A. (2002). Encouraging Knowledge Sharing: The Role of Organizational Reward Systems. Journal of Leadership \& Organizational Studies, 9(1), 6476. https://doi.org/10.1177/107179190200900105

Behringer, N., Sassenberg, K., \& Scholl, A. (2017). Knowledge Contribution in Organizations via Social Media. Journal of Personnel Psychology, 16(1), 12-24. https://doi.org/10.1027/18665888/a000169

Bellé, N. (2015). Performance-Related Pay and the Crowding Out of Motivation in the Public Sector: A Randomized Field Experiment. Public Administration Review, 75(2), 230-241. https://doi.org/10.1111/puar.12313

Bello, D., Leung, K., Radebaugh, L., Tung, R. L., \& van Witteloostuijn, A. (2009). From the Editors: Student samples in international business research. Advance online publication. https://doi.org/10.1057/JIBS.2008.101

Blau, P. M. (1964). Exchange and power in social life: With a new introduction by the author. New Brunswick: Transaction Publ.

Bock, G.-W., \& Kim, Y.-G. (2001). Breaking the Myths of Rewards: An Exploratory Study of Attitudes about Knowledge Sharing. PACIS 2001 Proceedings. (78), 1112-1125.

Bouwman, R., \& Grimmelikhuijsen, S. (2016). Experimental public administration from 1992 to 2014. International Journal of Public Sector Management, 29(2), 110-131. https://doi.org/10.1108/IJPSM-07-2015-0129

Bryant, S. E. (2003). The Role of Transformational and Transactional Leadership in Creating, Sharing and Exploiting Organizational Knowledge. Journal of Leadership \& Organizational Studies, 9(4), 32-44. https://doi.org/10.1177/107179190300900403 
Bundred, S. (2006). Solutions to Silos: Joining Up Knowledge. Public Money \& Management, 26(2), 125-130. https://doi.org/10.1111/j.1467-9302.2006.00511.x

Cabrera, Á., Collins, W. C., \& Salgado, J. F. (2006). Determinants of individual engagement in knowledge sharing. The International Journal of Human Resource Management, 17(2), 245264. https://doi.org/10.1080/09585190500404614

Chuang, C.-H., Jackson, S. E., \& Jiang, Y. (2016). Can Knowledge-Intensive Teamwork Be Managed? Examining the Roles of HRM Systems, Leadership, and Tacit Knowledge. Journal of Management, 42(2), 524-554. https://doi.org/10.1177/0149206313478189

Cress, U., \& Hesse, F.-W. (2004). Knowledge sharing in groups: Experimental findings of how to overcome a social dilemma. In Y. Kafai, W. Sandoval, \& N. Enyedy (Eds.), Proceedings of the 6th international conference on Learning sciences (pp. 150-157). 1149126: International Society of the Learning Sciences.

Currie, G., \& Suhomlinova, O. (2006). The Impact of Institutional Forces Upon Knowledge Sharing in the UK NHS: The Triumph of Professional Power and the Inconsistency of Policy. Public Administration, 84(1), 1-30. https://doi.org/10.1111/j.0033-3298.2006.00491.x

Dawes, S. S., Cresswell, A. M., \& Pardo, T. A. (2009). From "Need to Know" to "Need to Share": Tangled Problems, Information Boundaries, and the Building of Public Sector Knowledge Networks. Public Administration Review, 69(3), 392-402. https://doi.org/10.1111/j.15406210.2009.01987_2.x

Di Gangi, P. M., Wasko, M. M., \& Tang, X. (2012). Would You Share? International Journal of Knowledge Management, 8(1), 1-21. https://doi.org/10.4018/jkm.2012010101

Fischer, C. (2018a). Fostering Knowledge Sharing Behavior: preregistration. Retrieved from https://osf.io/r5jws/

Fischer, C. (2018b). Motivated to Share Your Knowledge? Development of a scale to measure knowledge sharing motives of public employees. Advance online publication. https://doi.org/10.31219/osf.io/r5xba

Gilson, L. L., Lim, H. S., Luciano, M. M., \& Choi, J. N. (2013). Unpacking the cross-level effects of tenure diversity, explicit knowledge, and knowledge sharing on individual creativity. Journal of Occupational and Organizational Psychology, 86(2), 203-222. https://doi.org/10.1111/joop.12011

Hanel, P. H. P., \& Vione, K. C. (2016). Do Student Samples Provide an Accurate Estimate of the General Public? PloS One, 11(12), e0168354. https://doi.org/10.1371/journal.pone.0168354

Hansen, M. T. (1999). The Search-Transfer Problem: The Role of Weak Ties in Sharing Knowledge across Organization Subunits. Administrative Science Quarterly, 44(1), 82-111. https://doi.org/10.2307/2667032

Hau, Y. S., Kim, B., \& Lee, H. (2016). What drives employees to share their tacit knowledge in practice? Knowledge Management Research \& Practice, 14(3), 295-308. https://doi.org/10.1057/kmrp.2014.32

Hau, Y. S., Kim, B., Lee, H., \& Kim, Y.-G. (2013). The effects of individual motivations and social capital on employees' tacit and explicit knowledge sharing intentions. International Journal of Information Management, 33(2), 356-366.

https://doi.org/10.1016/j.ijinfomgt.2012.10.009

Henry, P. J. (2008). Student Sampling as a Theoretical Problem. Psychological Inquiry, 19(2), 114-126. https://doi.org/10.1080/10478400802049951 
Henttonen, K., Kianto, A., \& Ritala, P. (2016). Knowledge sharing and individual work performance: An empirical study of a public sector organisation. Journal of Knowledge Management, 20(4), 749-768. https://doi.org/10.1108/JKM-10-2015-0414

Ipe, M. (2003). Knowledge Sharing in Organizations: A Conceptual Framework. Human Resource Development Review, 2(4), 337-359. https://doi.org/10.1177/1534484303257985

James, O., Jilke, S. R., \& van Ryzin, G. G. (Eds.) (2017). Experiments in public management research: Challenges and contributions. Cambridge, New York, NY, Port Melbourne, Delhi, Singapore: Cambridge University Press.

Kakar, A. K. (2018). How do team conflicts impact knowledge sharing? Knowledge Management Research \& Practice, 16(1), 21-31. https://doi.org/10.1080/14778238.2017.1401194

Kang, Y.-J., Kim, S.-E., \& Chang, G.-W. (2008). The Impact of Knowledge Sharing on Work Performance: An Empirical Analysis of the Public Employees' Perceptions in South Korea. International Journal of Public Administration, 31(14), 1548-1568. https://doi.org/10.1080/01900690802243607

Kelley, K. (2005). The Effects of Nonnormal Distributions on Confidence Intervals Around the Standardized Mean Difference: Bootstrap and Parametric Confidence Intervals. Educational and Psychological Measurement, 65(1), 51-69. https://doi.org/10.1177/0013164404264850

Kim, S., \& Lee, H. (2006). The Impact of Organizational Context and Information Technology on Employee Knowledge-Sharing Capabilities. Public Administration Review, 66(3), 370-385. https://doi.org/10.1111/j.1540-6210.2006.00595.x

Koenig, M. E.D. (1999). Education for Knowledge Management. Information Services \& Use, 19(1), 17-31. https://doi.org/10.3233/ISU-1999-19104

Lakens, D. (2017). Equivalence Tests: A Practical Primer for t Tests, Correlations, and MetaAnalyses. Social Psychological and Personality Science, 8(4), 355-362. https://doi.org/10.1177/1948550617697177

Law, K. K., Chan, A., \& Ozer, M. (2017). Towards an integrated framework of intrinsic motivators, extrinsic motivators and knowledge sharing. Journal of Knowledge Management, 21(6), 1486-1502. https://doi.org/10.1108/JKM-03-2016-0119

Lee, C. K., \& Al-Hawamdeh, S. (2012). Factors Impacting Knowledge Sharing. Advance online publication. https://doi.org/10.1142/S0219649202000169

Levallet, N., \& Chan, Y. E. (2016). Knowledge loss and retention: the paradoxical role of IT. In J. Liebowitz (Ed.), Successes and failures of knowledge management (pp. 97-111). Cambridge, MA: Elsevier/Morgan Kaufmann.

Lin, H.-F. (2007). Effects of extrinsic and intrinsic motivation on employee knowledge sharing intentions. Journal of Information Science, 33(2), 135-149. https://doi.org/10.1177/0165551506068174

Lin, H.-F., \& Lee, G.-G. (2004). Perceptions of senior managers toward knowledge-sharing behaviour. Management Decision, 42(1), 108-125. https://doi.org/10.1108/00251740410510181

Luen, T. W., \& Al-Hawamdeh, S. (2001). Knowledge management in the public sector: principles and practices in police work. Journal of Information Science, 27(5), 311-318. https://doi.org/10.1177/016555150102700502

March, J. G., \& Simon, H. A. (1958). Organizations. Cambridge, Mass.: Blackwell. 
McClelland, D. C. (1987). Human Motivation. Cambridge: Cambridge University Press.

Paulin, D., \& Suneson, K. (2012). Knowledge transfer, knowledge sharing and knowledge barriers-three blurry terms in KM. The Electronic Journal of Knowledge Management, 10(1), 81-91.

Peterson, R. A. (2001). On the Use of College Students in Social Science Research: Insights from a Second-Order Meta-analysis. Advance online publication.

https://doi.org/10.1086/323732

Polanyi, M. (1962). Personal knowledge: Towards \& post-critical philosophy. London: Routledge \& Kegan Paul.

Raymond, E. (1999). The cathedral and the bazaar. Knowledge, Technology \& Policy, 12(3), 2349. https://doi.org/10.1007/s12130-999-1026-0

Sandhu, M. S., Jain, K. K., \& Ahmad, I. U. (2011). Knowledge sharing among public sector employees: Evidence from Malaysia. International Journal of Public Sector Management, 24(3), 206-226. https://doi.org/10.1108/09513551111121347

Siciliano, M. D. (2017). Ignoring the Experts: Networks and Organizational Learning in the Public Sector. Journal of Public Administration Research and Theory, 27(1), 104-119. https://doi.org/10.1093/jopart/muw052

Siemsen, E., Roth, A., \& Balasubramanian, S. (2008). How motivation, opportunity, and ability drive knowledge sharing: The constraining-factor model. Journal of Operations Management, 26(3), 426-445. https://doi.org/10.1016/j.jom.2007.09.001

Srivastava, A., Bartol, K. M., \& Locke, E. A. (2006). Empowering leadership in management teams: Effects on knowledge sharing, efficacy, and performance. Academy of Management Journal, 49(6), 1239-1251. https://doi.org/10.5465/AMJ.2006.23478718

Tuan, L. T. (2019). HR Flexibility and Job Crafting in Public Organizations: The Roles of Knowledge Sharing and Public Service Motivation. Group \& Organization Management, 44(3), 549-577. https://doi.org/10.1177/1059601117741818

Van Baalen, P., van Dalen, J., \& van Malsen, J. (2013). Relational Model Conflicts in Knowledge Sharing Behavior. Retrieved from https://repub.eur.nl/pub/40100

Van Wijk, R., Jansen, J. J. P., \& Lyles, M. A. (2008). Inter- and Intra-Organizational Knowledge Transfer: A Meta-Analytic Review and Assessment of its Antecedents and Consequences. Journal of Management Studies, 45(4), 830-853. https://doi.org/10.1111/j.14676486.2008.00771.x

Vermeeren, B. (2017). Influencing public sector performance: studying the impact of ability-, motivation- and opportunity-enhancing human resources practices on various performance outcomes in the public sector. International Review of Administrative Sciences, 83(4), 717737. https://doi.org/10.1177/0020852315591642

Vong, S., Zo, H., \& Ciganek, A. P. (2016). Knowledge sharing in the public sector. Information Development, 32(3), 409-423. https://doi.org/10.1177/0266666914553604

Voorberg, W., Jilke, S., Tummers, L., \& Bekkers, V. (2018). Financial Rewards Do Not Stimulate Coproduction: Evidence from Two Experiments. Public Administration Review, 78(6), 864873. https://doi.org/10.1111/puar.12896

Vroom, V. H. (1967). Work and motivation. New York, NY: Wiley. 
Wang, S., Noe, R. A., \& Wang, Z.-M. (2011). Motivating Knowledge Sharing in Knowledge Management Systems. Journal of Management, 40(4), 978-1009. https://doi.org/10.1177/0149206311412192

Wells, L., \& Lesser, E. (1999). Managing organizational knowledge in a revenue agency: The experience of Washington, D.C. Government Finance Review, 21-23.

Wiswede, G. (2012). Einführung in die Wirtschaftspsychologie (5., aktualisierte Aufl.). UTB. München [u.a.]: Reinhardt.

Witherspoon, C. L., Bergner, J., Cockrell, C., \& Stone, D. N. (2013). Antecedents of organizational knowledge sharing: A meta-analysis and critique. Journal of Knowledge Management, 17(2), 250-277. https://doi.org/10.1108/13673271311315204

Yeo, R. K., \& Marquardt, M. J. (2015). To share or not to share? Self-perception and knowledge-sharing intent. Knowledge Management Research \& Practice, 13(3), 311-328. https://doi.org/10.1057/kmrp.2013.52

$\mathrm{Yu}, \mathrm{T} .-\mathrm{K}$. , Lu, L.-C., \& Liu, T.-F. (2010). Exploring factors that influence knowledge sharing behavior via weblogs. Computers in Human Behavior, 26(1), 32-41. https://doi.org/10.1016/j.chb.2009.08.002

Zhang, X., Pablos, P. O. d., \& Zhou, Z. (2013). Effect of knowledge sharing visibility on incentivebased relationship in Electronic Knowledge Management Systems: An empirical investigation. Computers in Human Behavior, 29(2), 307-313. https://doi.org/10.1016/j.chb.2012.01.029

\section{Stata packages}

Dinno A. 2017. tost: Two one-sided tests for equivalence. Stata software package. URL: https://www.alexisdinno.com/stata/tost.html 
Table 1. Vignette plan

\begin{tabular}{|c|c|c|}
\hline & Explicit knowledge & Implicit knowledge \\
\hline \multirow[t]{2}{*}{$\begin{array}{l}\text { Without } \\
\text { treatment } \\
\text { (control group) }\end{array}$} & $\begin{array}{l}\text { Vignette } 1 \\
\text { During a daily routine at your } \\
\text { workplace, you gathered information } \\
\text { from several sources. This could also } \\
\text { improve the work of your co-workers. }\end{array}$ & $\begin{array}{l}\text { Vignette } 4 \\
\text { During a daily routine at your workplace, } \\
\text { you had an experience that improved } \\
\text { your work process. This experience } \\
\text { could also help your co-workers. }\end{array}$ \\
\hline & $\begin{array}{l}\text { Please decide whether you will share } \\
\text { this information with your co-workers. } \\
(\mathrm{n}=319)\end{array}$ & $\begin{array}{l}\text { Please decide whether you will share } \\
\text { your knowledge with your co-workers. } \\
(\mathrm{n}=310)\end{array}$ \\
\hline \multirow[t]{3}{*}{$\begin{array}{l}\text { Appreciation } \\
\text { intervention } \\
\text { (intangible } \\
\text { incentive) }\end{array}$} & $\begin{array}{l}\text { Vignette } 2 \\
\text { During a daily routine at your } \\
\text { workplace, you gathered information } \\
\text { from several sources. This could also } \\
\text { improve the work of your co-workers. }\end{array}$ & $\begin{array}{l}\text { Vignette } 5 \\
\text { During a daily routine at your workplace, } \\
\text { you had an experience that improved } \\
\text { your work process. This experience } \\
\text { could also help your co-workers. }\end{array}$ \\
\hline & $\begin{array}{l}\text { You know that your co-workers } \\
\text { appreciate your knowledge sharing. }\end{array}$ & $\begin{array}{l}\text { You know that your co-workers } \\
\text { appreciate your knowledge sharing. }\end{array}$ \\
\hline & $\begin{array}{l}\text { Please decide whether you will share } \\
\text { this information with your co-workers. } \\
(\mathrm{n}=319)\end{array}$ & $\begin{array}{l}\text { Please decide whether you will share your } \\
\text { knowledge with your co-workers. } \\
(\mathrm{n}=307)\end{array}$ \\
\hline \multirow[t]{3}{*}{$\begin{array}{l}\text { Achievement } \\
\text { intervention } \\
\text { (tangible } \\
\text { incentive) }\end{array}$} & $\begin{array}{l}\text { Vignette } 3 \\
\text { During a daily routine at your } \\
\text { workplace, you gathered information } \\
\text { from several sources. This could also } \\
\text { improve the work of your co-workers. }\end{array}$ & $\begin{array}{l}\text { Vignette } 6 \\
\text { During a daily routine at your workplace, } \\
\text { you had an experience that improved } \\
\text { your work process. This experience } \\
\text { could also help your co-workers. }\end{array}$ \\
\hline & $\begin{array}{l}\text { You know that all shared information } \\
\text { improves your performance appraisal. }\end{array}$ & $\begin{array}{l}\text { You know that all shared information } \\
\text { improves your performance appraisal. }\end{array}$ \\
\hline & $\begin{array}{l}\text { Please decide whether you will share } \\
\text { this information with your co-workers. } \\
(\mathrm{n}=317)\end{array}$ & $\begin{array}{l}\text { Please decide whether you will share } \\
\text { your knowledge with your co-workers. } \\
(\mathrm{n}=309)\end{array}$ \\
\hline
\end{tabular}


Table 2. Sample description

\begin{tabular}{lrrrrr}
\hline Variable & Obs & Mean & Std. Dev. & Min & Max \\
\hline age & 609 & 45.10 & 10.29 & 22 & 80 \\
female & 618 & .61 & .49 & 0 & 1 \\
supervisor & 615 & .29 & .45 & 0 & 1 \\
tenure & 615 & 20.20 & 11.23 & 0 & 47 \\
fixed-term employm. & 613 & .05 & .23 & 0 & 1 \\
\hline
\end{tabular}


Table 3. Descriptive statistics, knowledge-sharing intention (KSI) after treatment

\begin{tabular}{lrrrrr}
\hline Variable & Obs & Mean & Std. Dev. & Min & Max \\
\hline KSI (without treatment) & 629 & 4.26 & .79 & 1 & 5 \\
KSI (appreciation treatment) & 625 & 4.27 & .82 & 1 & 5 \\
KSI (achievement treatment) & 627 & 4.28 & .80 & 1 & 5 \\
\hline KSI (vig. 1) & 319 & 4.23 & .80 & 1 & 5 \\
KSI (vig. 2) & 318 & 4.31 & .81 & 1 & 5 \\
KSI (vig. 3) & 318 & 4.27 & .83 & 1 & 5 \\
\hline KSI (vig. 4) & 310 & 4.29 & .78 & 1 & 5 \\
KSI (vig. 5) & 307 & 4.24 & .83 & 1 & 5 \\
KSI (vig. 6) & 309 & 4.29 & .78 & 1 & 5 \\
\hline
\end{tabular}


Table 4. Treatment effects on knowledge-sharing intention (within-subject analysis)

\begin{tabular}{|c|c|c|c|c|c|c|c|c|c|}
\hline \multirow[b]{2}{*}{ Estimates } & \multicolumn{4}{|c|}{ Significance test } & \multicolumn{4}{|c|}{ Equivalence test } & \multirow[t]{2}{*}{ Conclusion } \\
\hline & Z & $\mathbf{p}$ & d & $\mathrm{Cl}$ & $\mathbf{Z 1}$ & p1 & $\mathbf{Z 2}$ & p2 & \\
\hline \multicolumn{10}{|l|}{ Both kinds of knowledge } \\
\hline $\begin{array}{l}\text { appreciation treatment } \\
\text { vs. control }\end{array}$ & 1.647 & .096 & .015 & $\begin{array}{l}-.035 \text { to } \\
.065\end{array}$ & .353 & .362 & 3.647 & .0001 & $\begin{array}{l}\text { Significant but } \\
\text { equivalent }\end{array}$ \\
\hline $\begin{array}{l}\text { achievement treatment } \\
\text { vs. control }\end{array}$ & 1.532 & .126 & .024 & $\begin{array}{l}-.029 \text { to } \\
.077\end{array}$ & .468 & .319 & 3.532 & .0002 & Trivial difference \\
\hline $\begin{array}{l}\text { appreciation vs. } \\
\text { achievement treatment }\end{array}$ & .242 & .809 & -.007 & $\begin{array}{l}-.060 \text { to } \\
.046\end{array}$ & 1.758 & .039 & 2.242 & .013 & $\begin{array}{l}\text { Insignificant } \\
\text { difference }\end{array}$ \\
\hline \multicolumn{10}{|l|}{ Explicit knowledge } \\
\hline $\begin{array}{l}\text { appreciation treatment } \\
\text { vs. control }\end{array}$ & 3.231 & .001 & .09 & $\begin{array}{l}.027 \text { to } \\
.160\end{array}$ & $\begin{array}{l}- \\
1.231\end{array}$ & .891 & 5.231 & .0000 & $\begin{array}{l}\text { Significant but } \\
\text { equivalent }\end{array}$ \\
\hline $\begin{array}{l}\text { achievement treatment } \\
\text { vs. control }\end{array}$ & 1.816 & .069 & .048 & $\begin{array}{l}-.025 \text { to } \\
.121\end{array}$ & .184 & .427 & 3.816 & .0001 & $\begin{array}{l}\text { Significant but } \\
\text { equivalent }\end{array}$ \\
\hline $\begin{array}{l}\text { appreciation vs. } \\
\text { achievement treatment }\end{array}$ & 1.633 & .102 & 0.048 & $\begin{array}{l}-, 023 \text { to } \\
.119\end{array}$ & .367 & .357 & 3.633 & .0001 & Trivial difference \\
\hline \multicolumn{10}{|l|}{ Implicit knowledge } \\
\hline $\begin{array}{l}\text { appreciation treatment } \\
\text { vs. control }\end{array}$ & $\begin{array}{l}- \\
1.064\end{array}$ & .287 & -.067 & $\begin{array}{l}.140 \text { to } \\
-.007\end{array}$ & 3.064 & .001 & .936 & .175 & Trivial difference \\
\hline $\begin{array}{l}\text { achievement treatment } \\
\text { vs. control }\end{array}$ & 0.335 & .738 & -.002 & $\begin{array}{l}-.079 \text { to } \\
.076\end{array}$ & 1.665 & .048 & 2.335 & .0098 & $\begin{array}{l}\text { Insignificant } \\
\text { difference }\end{array}$ \\
\hline $\begin{array}{l}\text { appreciation vs. } \\
\text { achievement treatment }\end{array}$ & $\begin{array}{l}- \\
1.317\end{array}$ & .188 & -.65 & $\begin{array}{l}-.141 \text { to } \\
.011\end{array}$ & 3.317 & .001 & .683 & .247 & Trivial difference \\
\hline
\end{tabular}

Significance test: Wilcoxon signed-rank test. Equivalence test: two one-sided signed-rank test, equivalence type: epsilon expressed in units of z-distribution, equivalence level: 2 epsilon. So-called 'trivial differences' are insignificant but equivalent. 
Table 5. Differences between explicit and implicit knowledge sharing (between-subject analysis)

\begin{tabular}{l|ll|lllll|l}
\hline & \multicolumn{7}{|l|l}{ Significance test } & \multicolumn{3}{l|}{ Equivalence test } & Conclusion \\
Estimates & $\mathbf{Z}$ & $\mathbf{p}$ & $\mathbf{Z 1}$ & $\mathbf{p 1}$ & $\mathbf{Z 2}$ & $\mathbf{p 2}$ & \\
\hline $\begin{array}{l}\text { Control group (no } \\
\text { treatment) }\end{array}$ & -1.007 & .314 & 3.007 & .001 & .993 & .160 & Trivial difference \\
$\begin{array}{l}\text { Appreciation } \\
\text { treatment }\end{array}$ & 1.099 & .272 & .901 & .184 & 3.099 & .001 & Trivial difference \\
$\begin{array}{l}\text { Achievement } \\
\text { treatment }\end{array}$ & -.054 & .964 & 2.045 & .020 & 1.955 & .025 & Insignificant difference \\
\hline
\end{tabular}

Significance test: Wilcoxon rank sum test. Equivalence test: two one-sided rank sum test, equivalence type: epsilon expressed in units of z-distribution, equivalence level: 2 epsilon. 
Figure 1. Theoretical model

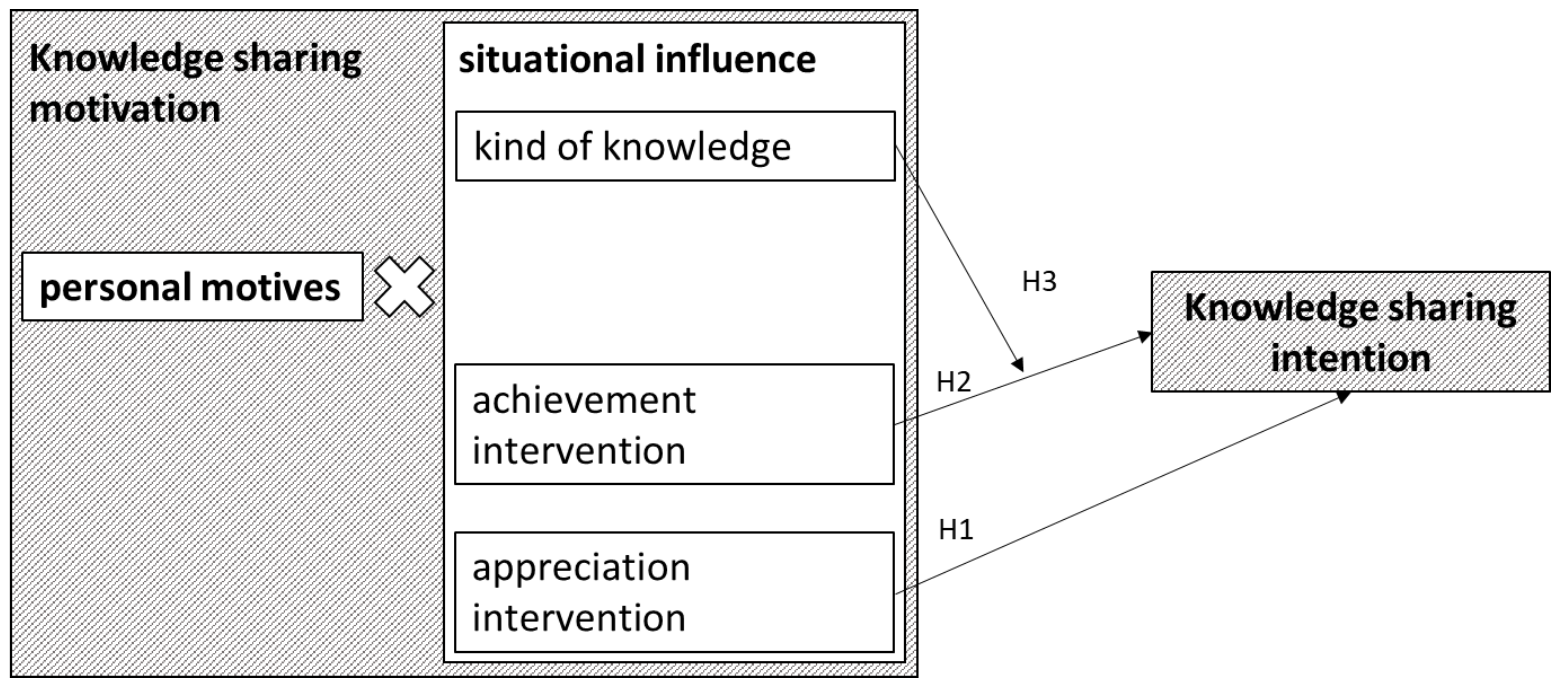

